Goldschmidt 2021 Abstract

https://doi.org/10.7185/gold2021.7268

\section{Biomineralization against all odds: Strategies of bacteria, foraminifera and bryozoa to control precipitation, mineralogy, and $\mathrm{pH}$ against environmental conditions.}

CAROLINE THALER ${ }^{1}$, DR. CLAIRE ROLLION-BARD ${ }^{2}$,

PASCALE LOUVAT ${ }^{3}$, ANNACHIARA BARTOLINI ${ }^{4}$, GUILLAUME PARIS ${ }^{5}$, BENEDICTE MENEZ ${ }^{6}$, MAGALI BONIFACIE $^{7}$ AND MAGALI ADER ${ }^{8}$

${ }^{1}$ IPGP

${ }^{2} \mathrm{LSCE}$

${ }^{3}$ IPGP - Institut de Physique du Globe de Paris

${ }^{4} \mathrm{MNHN}$

${ }^{5} \mathrm{CRPG}$

${ }^{6}$ Université de Paris, Institut de physique du globe de Paris, CNRS UMR 7154

${ }^{7}$ IPGP/CNRS UMR 7154

${ }^{8}$ Institut de Physique du Globe de Paris/CNRS UMR 7154

Presenting Author: thaler.caroline@gmail.com

Carbonate precipitation on Earth is a common process that led over time to huge carbon accumulation in sedimentary rocks. In the vast majority of cases, carbonate precipitation in seawater requires a biological agent and is accompanied by 3 major paradoxes. The first paradox is that, despite a saturation state favorable to the precipitation of carbonates in seawater, this reaction does not occur spontaneously. The second paradox is that current ocean chemistry should inhibit the formation of calcite, while it is a major polymorph in biominerals forming sedimentary rocks. The third paradox is that carbonate precipitation acidifies the immediate environment, which in theory is incompatible with sustained, massive carbonate formation.

Results from my recent work highlight some of the mechanisms that organisms deploy to solve these paradoxes. Three experimental strategies, proxies and phyla of biomineralizing organisms have been employed:

- During short culture experiments mimicking natural conditions, microbially mediated carbonatation was studied by using the recently developed clumped isotope $\left(\Delta_{47}\right)$ paleothermometer paired to traditional oxygen isotope ratios $\left(\delta^{18} \mathrm{O}\right)$. The results illustrate how dissolved inorganic carbon is processed by organisms prior to calcification [1]. It also showed for the first time that $\Delta_{47}$ values could simultaneously record information on both the precipitation fluid and the carbonate origin [2].

- In long-term culture experiments with extreme sulfate concentrations, foraminifera calcification was monitored. Foraminifera reproduction rate were high enough to permit the geochemical analyses on hundreds of specimens collected after several reproductions cycles in the media. Sulfur isotopes revealed how seawater chemistry is locally modified by organisms which allow calcite formation.

- Bryozoan carbonates were sampled in the vicinity of marine stations that record yearly environmental parameters. We measured boron isotopes were to reconstruct the $\mathrm{pH}$ value of the calcifying fluid and confront it to the lower environmental $\mathrm{pH}$ and its variations.

Overall, these results illustrate how organisms can increase calcium carbonate saturation state, provide a microenvironment suitable for the nucleation and growth of any polymorph of calcium carbonates, and maintain an elevated $\mathrm{pH}$ during carbonate precipitation.

[1] Thaler, et al., (2020). Biogeosciences, 17(7).

[2] Thaler, et al., (2018) Geochimica et Cosmochimica Acta, 199, 112-129. 